\title{
A Clinico-Epidemiological Study on Opportunistic Fungal Infection In HIV Patients And Its Corroboration With CD4 Cell Count
}

\author{
*Tapati Mondal ${ }^{1}$, Nilay Mandal $^{2}$, Purba Mukherjee ${ }^{3}$, Purushottam \\ Kumar $^{4}$,Chitrita Chattopadhyay ${ }^{5}$ \\ ${ }^{I}$ Assistant Professor,Dept. of Microbiology,Malda Medical College \&Hospital,India, \\ ${ }^{2}$ Associate Professor,Dept. Of General Surgery, Bankura Sammilani Medical College, India \\ ${ }^{3}$ Demonstrator,Dept. of Microbiology,Midnapore Medical College,Midnapore,India \\ ${ }^{4}$ Senior Resident, Dept. of General Surgery, AIIMS Patna,India \\ ${ }^{5}$ Professor,Dept. of Microbiology,Burdwan Medical College\&Hospital,India, \\ *Corresponding author: Tapati Mondall*
}

\begin{abstract}
The opportunistic mycoses are those fungal infections which are found in patients whose immunological defence mechanisms are weakened by cancer,AIDS, etc. In patient with AIDS, incidence of opportunistic mycoses are inversely correlated with the CD4 lymphocyte count. Our aim was to establish a correlation between fungal infections and $C D 4+T$ cell count, evaluate prevalence of fungal infections in $H I V$ patients, correlate fungal speciation and CD4+T cell count .SDA, SDCA, SDCCA were used as isolation culture media. Moulds and their species were identified by colony morphology and Teasing and LCB mount findings. Candida spp. was the most common(101, 94.39\%) isolated fungus followed by Aspergillus spp.(3.74\%) and Rhizopus spp. (1.87\%).Candida isolates were found in any ranges of CD4 cell count from 200 to less than 50, Aspergillus spp.was isolated from patients having CD4 cell count $<50$ and Rhizopus spp. were found in patients having CD4 cell count not more than 100. It was concluded that oral candidiasis is the commonest opportunistic fungal infections in HIV seropositive patients in this part of India. Almost all the patients having CD4 cell count less than 200.
\end{abstract}

Keywords: HIV seropositive patients, opportunistic fungal infections, Candida, CD4 cell count.

\section{Introduction}

Opportunistic infection is an infection in a patient with compromised defences by an agent of low virulence that would not produce infection in a normal patient. ${ }^{1}$ Compromised defences or immunodeficiencies may be classified as primary or secondary. Primary deficiencies in immunological function can arise through failure of any of the developmental process from stem cell to functional end cell. Acquired deficiencies can occur secondarily to a number of disease states or after exposure to drugs and chemicals. Viral infections are often immunosuppressive, for example, measles, HIV (Human Immunodeficiency Virus) viruses infect cell of the immune system. ${ }^{2,3}$

The HIV virus is recognized as the aetiological agent of the slowly progressing immunodeficiency in humans that culminates in development of AIDS (Acquired Immunodeficiency Syndrome). HIV is a retrovirusintegrates via a provirus in the human genome; thereby they can persist and potentially cause life-long damage to the immune system. The primary targets of HIV-1 infection are cluster-differentiated (CD4+) cells, especially $\mathrm{T}$ cells and the cells of the myeloid lineage, monocytes and macrophages. Secondary $\mathrm{T}$ cell deficiency is a cardinal feature of HIV infection and the paucity of CD4+ T cells and the lack of appropriate immune response facilitate numerous opportunistic infections. ${ }^{3}$ Opportunistic infections may be bacterial, viral, fungal or parasitic.

In patient with AIDS, the susceptibility and incidence of opportunistic mycoses are inversely correlated with the CD4 lymphocyte count. The data of fungal infections in HIV/AIDS patients in this geographical area and their spectrum of infections with relation to immunological profile are scarce. Hence our aim is to study the profile of fungal opportunistic infections and their relationship with the CD4+T lymphocyte profile.

\section{Materials And Methods}

The study was planned as a cross sectional observational study. One-hundred seven HIV seropositive cases with clinically detected possible fungal infection who were attending the Antiretroviral Therapy (ART) clinic of Burdwan Medical College and Hospital and willing to provide written informed consent, were included in the study. Data was included in a predesigned format (case report form). 
Collection of specimen -Specimens of throat swab, sputum, skin scrapings and nail clippings were collected by standardized aseptic methods. The specimens were transported promptly to the mycology laboratory and examined and cultured following standard methods. Direct Microscopy and Gram staining- Direct microscopy with $10 \% \mathrm{KOH}$ for skin samples and sputum samples and $20 \% \mathrm{KOH}$ for nail samples using recommended techniques. A smear was prepared from throat and oral swabs and examined under light microscope after gram staining following standard method. Culture and Isolation - All samples (skin and nail samples, throat and oral swab) were inoculated into the agar slant- Sabouraud's dextrose agar (SDA), Sabouraud's dextrose agar with chloramphenicol (SDCA), Sabouraud's dextrose agar with chloramphenicol and cycloheximide ( SDCCA) in the test tube. All cultures were incubated at $25^{\circ} \mathrm{C}$ and $37^{\circ} \mathrm{C}$ following standard protocol. Sputum samples were inoculated on SDA,SDCA slant in Mac Cartney's bottle and incubated at $25^{\circ} \mathrm{C}$ and $37^{\circ} \mathrm{C}$ and all cultures were incubated for at least 3 weeks. and examined at frequent intervals for developing colonies. Isolated colonies on Sabourauds agar were used for identification. Further identification of fungal isolates was done by standard recommended procedure.

Identification of Candida and Candida species- Colony morphology, Gram staining findings presumed to be Candida spp. were further processed for species identification by Germ Tube Test, Chlamydospore formation in corn meal agar, subculture on CHROM agar and Biochemical Test- sugar fermentation and assimilation test following standard method. Identification of moulds- Moulds and their species were identified by colony morphology and Teasing and LCB mount findings under light microscope following standard method.

\section{Results}

Out of 107 HIV positive cases, 60 cases $(56.07 \%)$ were male and rest 47 cases $(43.93 \%)$ were female. Maximum number of cases were found to be of the age group of 21-40 years (83.18\%) followed by 41-60 years $(10.28 \%)$ and below 20years $(6.54 \%)$. Most of the cases of the study population reside in rural area $(66.36 \%)$ and rest of the population $(33.64 \%)$ from urban. It was found that heterosexual transmission $(87.85 \%)$ was the most common mode of transmission. Others were vertical transmission $(3.74 \%)$, blood \& blood products $(1.87 \%)$, and contaminated needles $(0.93 \%)$. According to distribution of the study group on the basis of their occupation, it was seen that majority of the patients were labourers $(22.43 \%)$ and zari workers $(10.28 \%)$ followed by truck drivers (7.48\%), service man (6.54\%), businessman and bus drivers (both $3.74 \%$ ), farmer $(2.80 \%)$ and others. Among the female patients, majorities were house-wives $(26.17 \%)$. Among the study population, $30.84 \%$ patients were having associated tuberculosis. The most common clinical presentation was fever followed by weight loss, cough and diarrhoea. Candida spp. (94.39\%) was the most common isolated species among all cases of fungal infection in the study group followed by Aspergillus spp. (3.74\%) and Rhizopus spp. (1.87\%)[Table 1].

Table 1: Distribution of different fungal infection in the study population

\begin{tabular}{|l|l|l|}
\hline Fungal infection & Number & Percent \\
\hline Candida spp. & 101 & 94.39 \\
\hline Aspergillus spp. & 4 & 3.74 \\
\hline Rhizopus spp. & 2 & 1.87 \\
\hline
\end{tabular}

It was found that among the isolated Candida species in the present study population, most common species was Candida albicans (91.09\%) followed by Candida krusei (4.95\%), Candida tropicalis (1.98\%) and Candida parapsillosis ( 1.98\%). Among the isolated 3.74\% Aspergillus spp. all were Aspergillus fumigatus. It was found that CD4 cell count was less than 50 in $20.56 \%$ of patients, 51 to 100 in $25.23 \%$ of patients, 101 to 150 in $28.04 \%$ of patients, $151-200$ in $23.36 \%$ of patients and more than 200 in $2.80 \%$ of patients. In this study it was found that candida isolates were found in any ranges of CD4 cell count from less than 50 to 200. Candida isolated only from three patients having CD4 count $>200$. In this study Aspergillus spp. was isolated from patients having CD4 cell count $<50$ and Rhizopus spp. were found in patients having CD4 cell count not more than $100[$ Table 2].

Table 2: CD4 cell count and other fungal infections

\begin{tabular}{|l|l|l|}
\hline CD4 cell count & Aspergillus fumigatus & Rhizopus spp. \\
\hline Less than 50 & 4 & 1 \\
\hline $51-100$ & 0 & 1 \\
\hline
\end{tabular}

\section{Discussion}

107 cases were recruited from the HIV positive patients attending the ART clinic at Burdwan Medical College and Hospital,a tertiary care hospital in West Bengal,India. Sample processing was done in the Department of Microbiology, Burdwan Medical College. Among the 107 HIV positive cases under study, 
maximum HIV positive cases were in the age group of 21-40years $(83.18 \%, 89 / 107)$ with a male preponderance $(56.07 \%, 60 / 107)$ which is concordant with many other studies. ${ }^{5,6,7}$ Heterosexual contact $(87.85 \%)$ was the most common route of transmission in this study which correlates well with other studies.$^{7} 8$ According to distribution of the study group on the basis of their occupation, it was seen that majority of the patients were labourers $(22.43 \%)$ and zari workers $(10.28 \%)$ followed by truck drivers $(7.48 \%)$, service man $(6.54 \%)$, businessman and bus drivers (both $3.74 \%$ ), farmer $(2.80 \%)$ and others. The differences between various studies could be explained by largely due to the differences in the occupational patterns and the source from where the patients were selected. 6, 9, 10,11

Among the study population, $30.84 \%$ patients were having associated tuberculosis. This association is concordant with many other studies. ${ }^{12,13}$ In the present study, majority of patients had more than one symptom. Fever and weight loss were the predominant symptoms, followed by cough and diarrhea. Anand. K. Patel and his colleagues reported in their study that cough was the most common symptom, other common symptoms were fever and weight loss. ${ }^{5}$ In another study in Varanasi, fever $(70.6 \%)$, weight loss $(53.3 \%)$ were the predominant symptoms, and others were chronic diarrhoea $(43.9 \%)$ and cough $(40.3 \%){ }^{14}$

Among the 107 fungal isolates, one hundred one (101/107, 94.39\%) were Candida spp., four (4/107, $3.74 \%)$ were Aspergillus spp. and two $(2 / 107,1.87 \%)$ were Rhyzopus spp. . Wadhwa et al ${ }^{15}$ reported in their study in North India that candidiasis was the most common diagnosis $(41.7 \%)$, followed by cryptococcosis $(10.0 \%)$ and aspergillosis (8.3\% each). In another study in Bologna, it was found that most common fungal isolate was candida $(56 / 74,75.68 \%)$, and aspergillosis were $5.40 \%(4 / 74) .{ }^{16}$ In our study, candida was the most common isolate, followed by aspergillus and rhizopus. Among the 101 Candida isolates, 89 were isolated from throat and oral swab and rest 12 were isolated from skin \& nail samples. All the Candida isolates from skin and nail were $C$. albicans. Among the 89 oromucosal candida isolates, C. albicans was $89.89 \%$ (80/89), rest were non-albicans Candida spp. (10.11\%).

Sangeeta D. Patel et al. repoted in their study that out of 33 isolates from oral lesions, 27 were Candida albicans $(81.8 \%)$ and 6 were non-albicans Candida spp. (18.2\%). ${ }^{6}$ In another study at Aurangabad, Baradkar et al. reported that from oral lesions $76.92 \%$ were identified as $C$. albicans and rest were other Candida spp. $23.08 \%$ ). ${ }^{17}$ These were comparable to our stud. In a study ${ }^{18}$ it was reported that oral candidiasis was the most common (59.00\%) opportunistic infection and this finding is similar to the report of NACO ${ }^{19}$ and $\mathrm{T} \mathrm{K}$ Giri et al. $^{20}$ In one study at Nagpur, it was reported that oral candidiasis was significantly correlated to a reduced CD4 cell count below 200 cells $/ \mathrm{mm}^{3}{ }^{21}$

In another study at Mumbai, it was reported that out of 40 patients with oral candidiasis, 28 patients had CD4 count $<200$ (group A), 10 patients were in group, B (CD4 count 200-500 cell//mm ${ }^{3}$ ) and 2 patients in group $\mathrm{C}\left(\mathrm{CD} 4>500 \mathrm{cell} / \mathrm{mm}^{3}\right) .{ }^{22}$ In our study it was found that out of 101 patients with candidiasis, all most all (98/101) had CD4 count $<200$ and only 3 patients had CD4 count $>200$.

In our study, four cases of aspergillosis had CD4 count <50. A study in Japan revealed that remarkable risk factor of HIV-related aspergillosis was decrease of CD4 cell count less than $10 / \mu 1$, in addition to the usual risk factors of aspergillosis. ${ }^{23}$ In another study in USA, it was reported that neutropenia, a CD4 count <30 cells $/ \mathrm{mm}^{3}$, corticosteroid use, and Pneumocystis carinii infection were associated with subsequent identification of Aspergillus in respiratory specimens. ${ }^{24}$ In one study it was reported that human zygomycosis caused by the Mucorales generally occurs in immunocompromised hosts as opportunistic infections. Host risk factors include diabetes mellitus, neutropenia, sustained immunosuppressive therapy, chronic prednisone use, iron chelation therapy, broad-spectrum antibiotic use, severe malnutrition, and primary breakdown in the integrity of the cutaneous barrier, with rhinocerebral and pulmonary diseases being the most common manifestations. ${ }^{25}$ In another study in India it was reported that the most common manifestation of mucormycosis is rhino-cerebral form. Most affected patients are diabetics, especially poorly controlled with ketoacidosis, patients on immunosuppressive treatment, desferioxime treatment and HIV and patients with malignancies. ${ }^{26}$ In our study, Rhizopus was isolated from two patients- both the patients were forty years males with history of diabetes mellitus.

\section{Conclusion}

In this clinico-epidemiological cross-sectional observational study, 107 HIV positive patients were recruited and samples were taken from different sites according to the presenting symptoms. They were also enquired for the presence of the risk factors relating to HIV infection along with other relevant data. Among the 107 HIV positive cases under study, maximum HIV positive cases were in the age group of 21-40years $(83.18 \%, 89 / 107)$ which is the sexually active age, with a male preponderance $(56.07 \%, 60 / 107)$ which is comparable to other studies. From the relevant data it was concluded that HIV is more common among migrant labourers and heterosexual sex was the most common mode of transmission. Among the study population, $30.84 \%$ patients were having associated tuberculosis. Associated tuberculosis is concordant with many other studies. 
It was found that Candida $(94.39 \%)$ was the commonest fungal isolate among the opportunistic fungal infections and oral candidiasis was the most common opportunistic fungal infection. Most common species was Candida albicans. These are comparable to other studies. Among the isolated candidiasis patients all most all had CD4 count $<200$ and it is comparable to other studies. People having CD4 count less than 50 are more prone to infection with filamentous fungus. In our study isolated four cases of aspergillosis had CD 4 count $<50$. It is concluded that oral candidiasis is the commonest opportunistic fungal infections in the HIV seropositive patients in this part of India. Almost all the patients with fungal opportunistic infections having CD4 cell count less than 200.

\section{References}

[1]. Washington Winn Jr., Stephen Allen, William Janda, Elmer Koneman, Gary Procop, Paul Schreckenberger, Gail Woods, eds. Introduction to Microbiology. In: Koneman's Color Atlas and Textbook of Diagnostic Microbiology .6 ${ }^{\text {th }}$ ed. United State of America: LWW;2006:01-66

[2]. Stewart J. Innate and acquired immunity. In: Greenwood David, Slack Richard, Peutherer John, Barer Mike, eds. Medical Microbiology. $17^{\text {th }}$ ed. United States of America: Churchill Livingstone;2007:107-133.

[3]. Ignatius Ralf and Schneider Thomas. Acquired immunodeficiencies. In: Kaufmann Stefan H.E. and Steward Michael W,eds. Topley and Wilson's Microbiology \& Microbial infections Immunology.10 ${ }^{\text {th }}$ ed. Great Britain:Hodder Arnold;2005:787-815.

[4]. Brooks Geo. F, Carrol Karen C, Butel Janet S, Morse Stephen A, Mietzner Timothy A. AIDS \& Lentiviruses. In: Jawetz, Melnick, \& Adelberg's Medical Microbiology. 25 ${ }^{\text {th }}$ ed. United States of America; The McGraw-Hill, 2004:625-664.

[5]. Patel Anand K, Thakrar Sandip J, Ghanchi Feroz D. Clinical and laboratory profile of patients with TB/HIV coinfection: A case series of 50 patients. Lung India. 2011; 28(2): 93-96.

[6]. Patel Sangeeta D., Kinariwala Dipa M., Javadekar Tanuja B. Clinico-microbiological study of opportunistic infection in HIV seropositive patients. Indian J Sex Transm Dis. 2011; 32(2): 90-93.

[7]. Ranganathan K, Umadevi M, Saraswathi TR, Kumarasamy N, Solomon S, Johnson N. Oral lesions and conditions associated with Human Immunodeficiency Virus infection in 1000 South Indian Patients. Ann Acad Med Singapore. 2004;33(4):375-425.

[8]. Annual Report 2009-2010 by Department of AIDS Control, Ministry of Health and Family Welfare, National AIDS Control Organization, Government of India. Page No. 1. [last updated on 2010 Mar 22, Last accessed on 2010 Dec 22]. Available from: http://www.nacoonline.org.

[9]. Mohanty KC, Sundrani RM, Nair S. HIV infection in patients with respiratory disease. Indian J Tuberc. 1993;40:5.

[10]. Rajasekaran R, Lima A, Kamakshi S, Jeyaganesh D, Senthamizhchelvan A, Savithrr S, et al. Trend of HIV infection in patients with tuberculosis in rural south India. Indian J Tuberc. 2000;47:223.

[11]. Bhagyabati DS, Naorem S, Singh TJ, Singh KB, Prasad L, Shantidevi T. HIV and TB Co-infection. Journal, Indian Academy of Clinical Medicine. 2005;6:220.

[12]. Ghiya Ragini, Naik Eknath, Casanas Beata, Izurieta Ricardo, Marfatia Yogesh, et al. Clinico-epidemiological profile of HIV/TB coinfected patients in Vadodara, Gujarat. Indian J Sex Transm Dis. 2009; 30(1): 10-15.

[13]. Rajasekaran S, Mahilmaran A, Annadurai S, Kumar S, Raja K. Manifestation of tuberculosis in patients with human immunodeficiency virus: a large Indian study. Ann Thorac_Med. 2007; 2(2):58-60.

[14]. Chakravarty J, Mehta H, Parekh A, Attili SV, Agrawal NR, Singh SP, Sundar S. Study on clinico-epidemiological profile of HIV patients in eastern India. J Assoc Physicians India. 2006; 54:854-7.

[15]. Wadhwa A, Kaur R, Agarwal SK, Jain S, Bhalla P. AIDS-related opportunistic mycoses seen in a tertiary care hospital in North India. J Med Microbiol. 2007; 56(Pt 8):1101-6.

[16]. Manfredi R, Nanetti A, Mazzoni A, Mastroianni A, Chiodo F. The incidence, etiology and clinical significance of visceral mycoses in patients with AIDS. Minerva Med. 1993; 84(7-8):383-91.

[17]. Baradkar VP, Karyakarte RP. Isolation and characterization of Candida species in Acquired Immuno Deficiency Syndrome. Indian J Med Microbiol. 1999; 17:42-4.

[18]. A Singh, I Bairy, PG Shivananda. Spectrum of opportunistic infections in AIDS cases. 2003; vol (57): 16-21.

[19]. National guidelines for clinical management of HIV/AIDS. National AIDS Control Organisation, Ministry of Health and Family Welfare. New Delhi: Government of India; 2000. p. 17-52.

[20]. Giri TK, Pande I, Mishra NM, et al. Spectrum of clinical and laboratory characteristics of HIV infection in Northern India J Com Dis 1995;27:131-41.

[21]. Bodhade AS, Ganvir SM, Hazarey VK. Oral manifestation of HIV infection and their correlation with CD4 count.J Oral Sci. 2011; 53(2):203-11.

[22]. Subodh Arun Sontakke, HR Umarji, Freny Karjodkar. Comparison of oral manifestations with CD4 count in HIV-infected patients. 2011; vol(22):732.

[23]. Yasuoka A. Fungal Infections in HIV-infected patients. Nihon Ishinkin Gakkai Zasshi. 2006;47(3):161-6.

[24]. Wallace JM, Lim R, Browdy BL, Hopewell PC, Glassroth J, Rosen MJ, Reichman LB, Kvale PA. Risk factors and outcomes associated with identification of Aspergillus in respiratory specimens from persons with HIV infection study group. Chest. 1998; 114(1):131-7.

[25]. Julie A. Ribes, Carolyn L. Vanover Sams, Doris J. Baker. Zygomycetes in Human Disease. Clin Microbiol Rev. 2000 ; 13(2): 236301 .

[26]. Patel Atul K, Vora Himanshu J, Patel Ketan K, Patel Bhavin. Elderly Diabetic Patients with Surgical Site Mucormycosis Extending to Bowel. J Glob Infect Dis. 2010; 2(2): 186-188. 